\title{
Addressing Sexual Violence in Mental Health Settings: recruitment and retention of patients in a randomized trial
}

\begin{abstract}
Andrea Feijó Mello; Bruno Messina Coimbra; Thauana Oliveira-Watanabe; Cecilia Roberti Proença; Ana Teresa D’Elia; Mariana Rangel Maciel; Bruna S. Nicoletta; Nina Marques Valente; Mary S. Lin Yeh; Marcelo Feijó Mello
\end{abstract}

Department of Psychiatry, Universidade Federal de São Paulo, São Paulo, Brazil

\section{BACKGROUND:}

There are over 50 thousand yearly reports of sexual assault in Brazil, although evidence suggests that underreporting is significant.

- $45-50 \%$ of women will develop PTSD following exposure to sexual assault (Luz et al. 2016)

- Access to PTSD specialized treatment in the Brazilian public health care system is limited.

\section{OBJECTIVES}

Describe the enrollment phase of a randomized clinical trial (RCT) aiming to include 100 recently sexually assaulted women with PTSD.

\section{MATERIALS AND METHODS: FIGURE 1: STUDY DESIGN}

We evaluated women admitted at Hospital Pérola Byington aged 18-45 who suffered sexual assault up to six months, screened for PTSD.

- Inclusion criteria: PTSD diagnosis according to the DSM-5 and CAPS-5, signed informed consent.

- Exclusion criteria: present substance abuse, intellectual disability, other acute illnesses not under control, pregnancy.

RESULTS: FIGURE 2

- 149 women were referred to specialized treatment

- 34 refused any intervention, 3 did not respond; 12 not eligible

- 100 arrived for screening at PROVE-UNIFESP

- 74 were diagnosed with PTSD and were enrolled in treatment

- 22 women dropped-out before the $14^{\text {th }}$ weeks (independent of the treatment arm, SERT X IPT)

- $46 \%$ of evaluated women, being $62 \%(n=46 / 74)$ of enrolled ones, completed 14 weeks of treatment

- the study is still ongoing to complete the one year follow-up

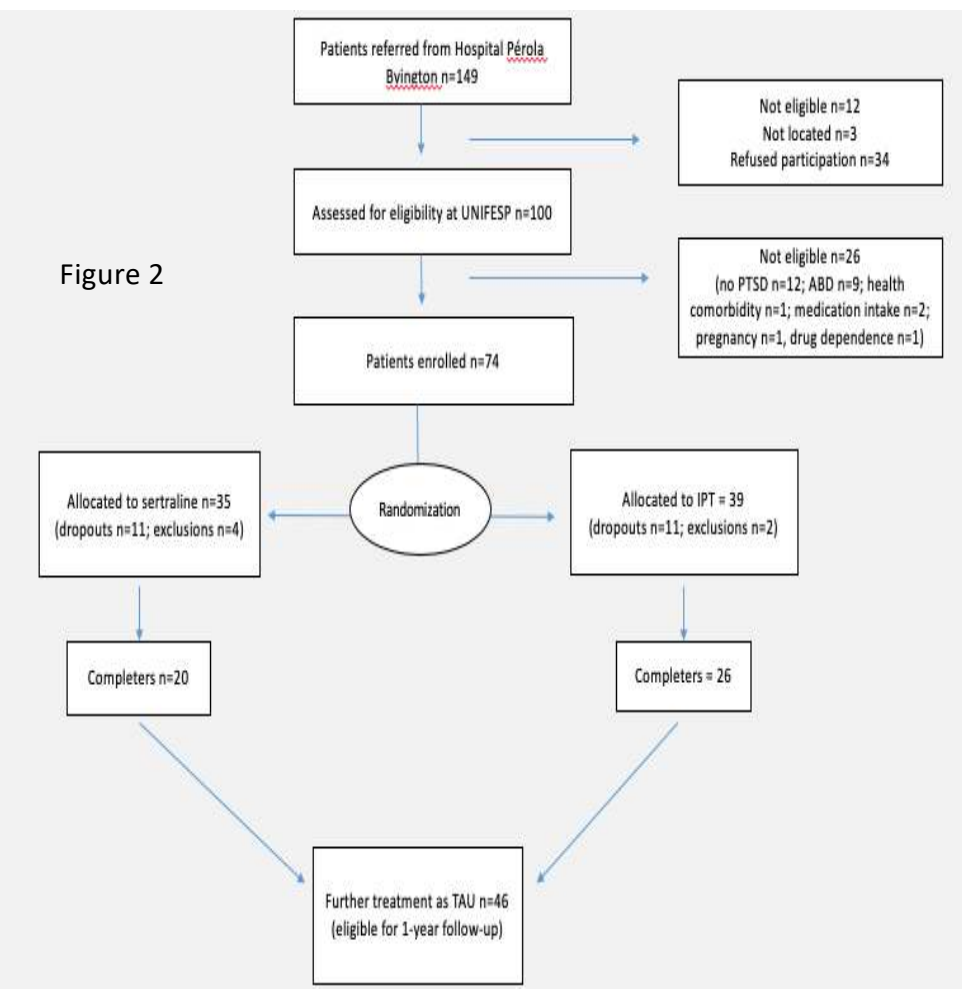

CONCLUSIONS: Refusal of mental treatment and dropout rates were high in sexually assaulted women with PTSD, more studies are necessary to understand treatment refusal with this specific population that has a high risk for PTSD.

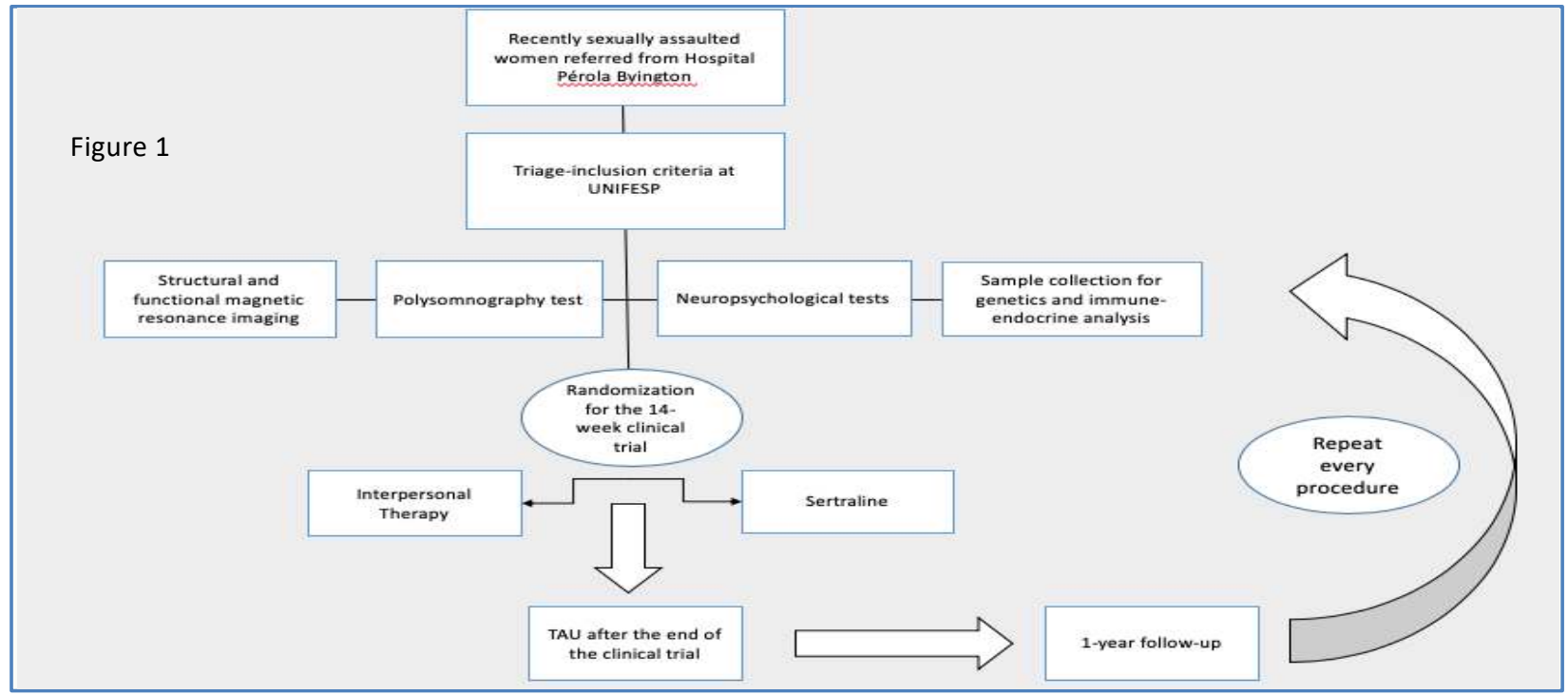

Luz MP, Coutinho ES, Berger W, Mendlowicz MV, Vilete LM, Mello MF, et al. Conditional risk for posttraumatic stress disorder in an epidemiological study of a Brazilian urban population. J Psychiatr Res. 2016;72:51-7. 